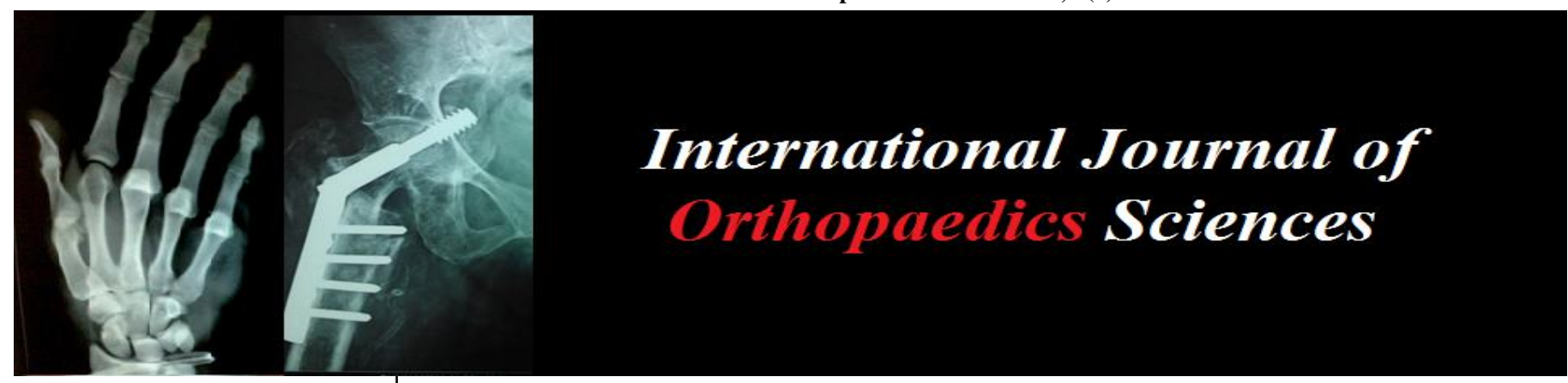

E-ISSN: 2395-1958

P-ISSN: 2706-6630

IJOS 2021; 7(2): 270-274

(C) 2021 IJOS

www.orthopaper.com

Received: 09-02-2021

Accepted: 18-03-2021

Siddalingeshwar Vithoba Honnur Associate Professor, Dept. of Orthopaedics, The Oxford Medical College, Hospital \& Research Centre, Yadavanahalli Attibele, Bangalore, Karnataka, India

Mohammed Tauheed

Professor,

Dept. of Orthopaedics, The

Oxford Medical College, Hospital

\& Research Centre,

Yadavanahalli, Attibele,

Bangalore, Karnataka, India

Mohammed Shahid

Junior Resident, Dept. of Orthopaedics, Yenepoya Medical College, University Road,

Yenepoya University Campus,

Deralakatte, Karnataka, India
Corresponding Author: Siddalingeshwar Vithoba Honnur Associate Professor, Dept. of Orthopaedics, The Oxford Medical College, Hospital \& Research Centre, Yadavanahalli, Attibele, Bangalore, Karnataka, India a

\section{Surgical outcome of intra-articular fractures of distal end of radius managed by external fixator - our experience}

\author{
Siddalingeshwar Vithoba Honnur, Mohammed Tauheed and Mohammed \\ Shahid
}

DOI: https://doi.org/10.22271/ortho.2021.v7.i2d.2642

\section{Abstract}

Background \& Objectives: Preservation of the articular congruity is the principle prerequisite for successful recovery following distal radius fractures. The best method of obtaining and maintaining an accurate restoration of articular anatomy however, remains a topic of considerable controversy. External fixation as a method of treatment for distal end of radius fracture has more than $60 \mathrm{yrs}$ of documented clinical experience. The main aim of this study is to evaluate the results obtained by treatment of distal end radius fractures by external fixation.

Methods: In a prospective controlled study, 30 cases of intra-articular fractures of distal end radius in adult patients were treated with uniplanar bridging type of external fixation using the principle of ligamentotaxis and augmentation by $\mathrm{K}$ wires. Mean age of the patients was 37.3years, External fixator was applied for a mean duration of 6 weeks and cases were followed up for an average of 37.0 weeks post operatively.

Results: Assessed as per De merit point system of Gartland and Werley (modified by Sarmiento 1975) for functional results at the end of 6 months of follow up. Excellent to good functional result was noted in $83.3 \%$.

Conclusion: External fixation and ligamentotaxis provides better functional and anatomical results in intra-articular fractures of distal end radius. The success not only depends on the anatomical restoration of the articular surface. It also depends on the associated soft tissue injuries and articular damage.

Keywords: External fixator, ligamentotaxis, intra-articular fractures, distal end radius

\section{Introduction}

Fractures involving the distal end of radius are one of the most common injuries encountered in orthopedics. In fact these injuries are the most common fractures of the upper extremity and account for approximately 1/6th $(16 \%)$ of all fractures seen and treated in emergency rooms ${ }^{[1-3]}$ Intra-articular fractures can jeopardize the integrity of the articular congruence and kinematics of these articulations. Distal radius fractures especially the high energy fractures are often associated with poor results and high complication rates, In order to treat these fractures optimally, we must understand the extent of displacement, the degree of articular disruption ${ }^{[4}$, 5], the stability and reducibility of each fracture as well as any concurrent injury to adjacent nerves, tendons or carpal structures, must be assessed carefully.

For an optimal result to occur there must be an accurate restoration of skeletal anatomy 6 and most importantly supervised rehabilitation by skilled physiotherapy. Preservation of the articular congruity is the principle prerequisite for successful recovery. The best method of obtaining and maintaining an accurate restoration of articular anatomy however, remains a topic of considerable controversy.

The successful use of external fixation in the management of unstable intra- articular fractures necessitates careful assessment of the fracture pattern, appropriate patient selection, meticulous surgical technique, appropriate choice of fixation devices, careful post operative monitoring and aggressive early rehabilitation ${ }^{[7]}$.

Ligamentotaxis alone regardless of the method is prone for failure in cases where articular congruity cannot be restored by closed reduction. 
Supplementation with K- wire internal fixation has proved to be reliable method of maintaining an accurate reduction in these cases ${ }^{[8]}$

\section{Material and Methods}

We conducted Prospective study of 30 cases of intraarticular fracture of distal end radius in adult patients in the department of Orthopedics at The Oxford Medical College, Bangalore during the study period of 2 year from august 2018 to July 2020.

Assessment of fractures of distal end radius was done with Radiographs of injured wrist with Posteroanterior view and Lateral view.

Radiographic parameters noted were:

a. Radial inclination in PA view

b. Radial length in PA view

c. Palmar tilt in lateral view

d. Articular step off / displacement

Fractures were classified according to Frykman's classification ${ }^{[9]}$.

Instability was recognized based upon initial displacement: $>20^{\circ}$ dorsal angulation, marked dorsal metaphyseal communition, radial shortening $>10 \mathrm{~mm}$.

Criteria for acceptable reduction (Melone) were:

- $2 \mathrm{~mm}$ articular incongruity

- $<10^{0}$ loss of radial inclination ( $>15^{0}$ radial inclination)

- $\quad<2 \mathrm{~mm}$ volar or dorsal translation

- $<10^{0}$ residual dorsal tilt (b/w $15^{0}$ dorsal tilt and $20^{\circ}$ volar tilt)

- $\quad<5$ mm radial shortening

\section{Surgical Technique}

Under General anaesthesia (20 cases) / Brachial Block (10 cases), the patient was placed supine on the operation table.
No Tourniquet was used. The arm, Forearm, hand was scrubbed and prepared. The limb was placed on side board. Under C arm control closed reduction of the fracture was carried out. Two stab incisions, one at the lateral aspect of the second metacarpal at the base and another one inch distal to it and it was drilled with $1.5 \mathrm{~mm}$ drill bit, and then fixed with $2.5 \mathrm{~mm}$ schanz screws. Another two stab incisions were made, the first approximately $8 \mathrm{cms}$ proximal to fracture site and another one inch proximal to the first incision. Taking care not to injure the tendons, nerves and vessels (bare area), drill sleeve fixed centrally, through the drill sleeve radius was drilled with $2.5 \mathrm{~mm}$ drill bit and with T-handle $3.5 \mathrm{~mm}$ schanz screws were fixed through each incision and penetrating both cortex of the radius. The distraction rod was then connected to the 4 schanz pin by means of clamps. Under image intensifier guidance, further distraction if necessary was carried out by the fixator.

\section{Post-Operative care and Rehabilitation.}

Immediate post-operative check $\mathrm{X}$-rays were taken in both PA and lateral views.

The patient was called for inspection and dressing change at the interval of one week for the next 6 weeks. The patient was assessed subjectively for pain at the fracture site; clinically for tenderness and loosening of the pins. The external fixator removed after six weeks without anaesthesia.

Check x-ray was taken in both AP and lateral view. The range of motion at the wrist was recorded and any deformity was assessed Physiotherapy was carried out regularly for 2 weeks. All the cases were followed at an interval of 6 weeks, 3 months \& 6 months. The follow up ranged from 1 month to 6 month with an average of 3 months.

There was loosening of pins in one case during fourth week for which fixator removed in fifth week. Following removal no displacement noted.
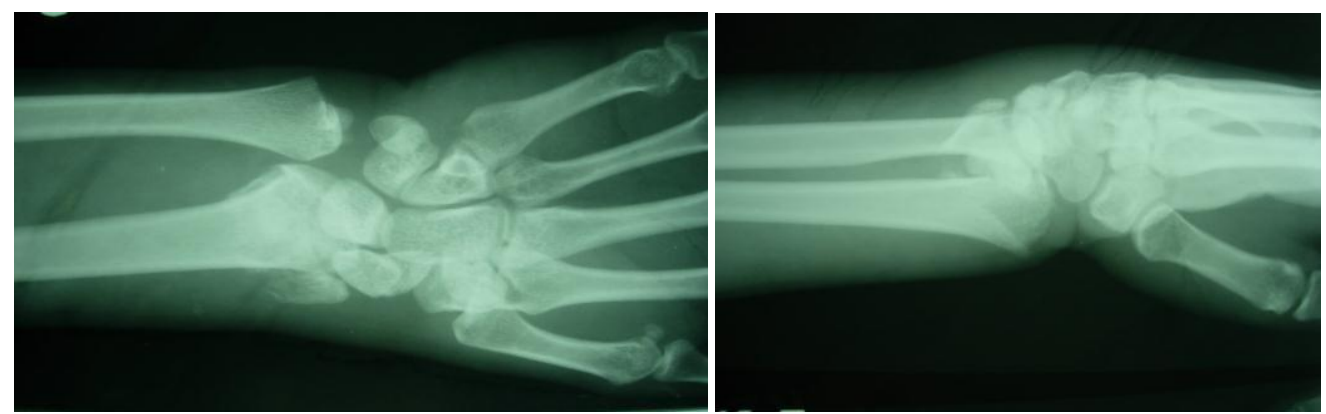

Pre-Operative X-Ray Ap And Lateral
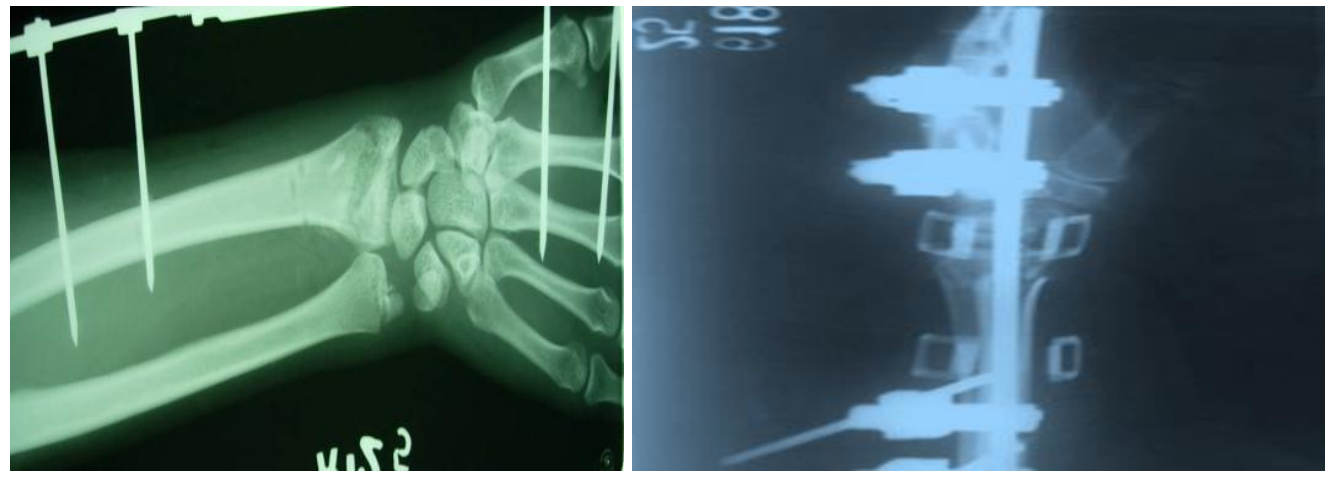

Check X-RAY 

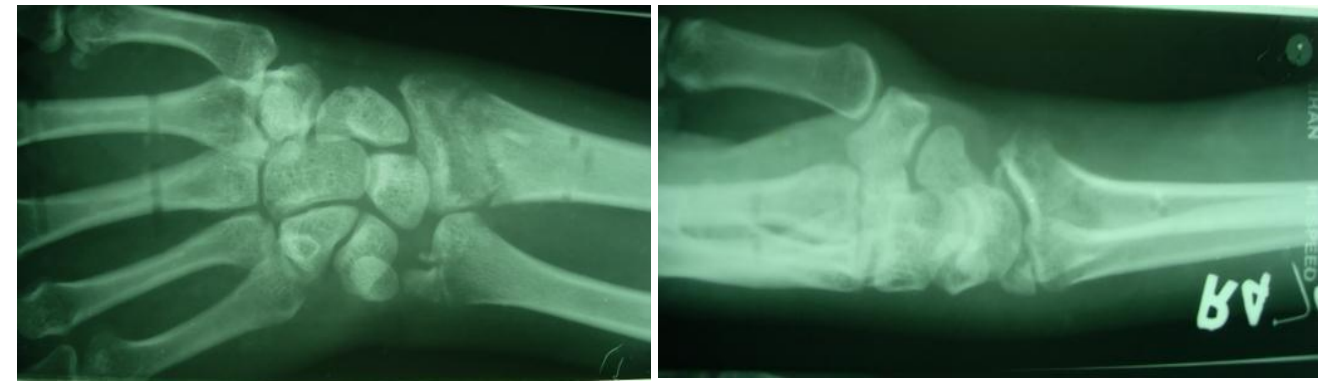

6-Week-Old X-Ray Ap And Lateral
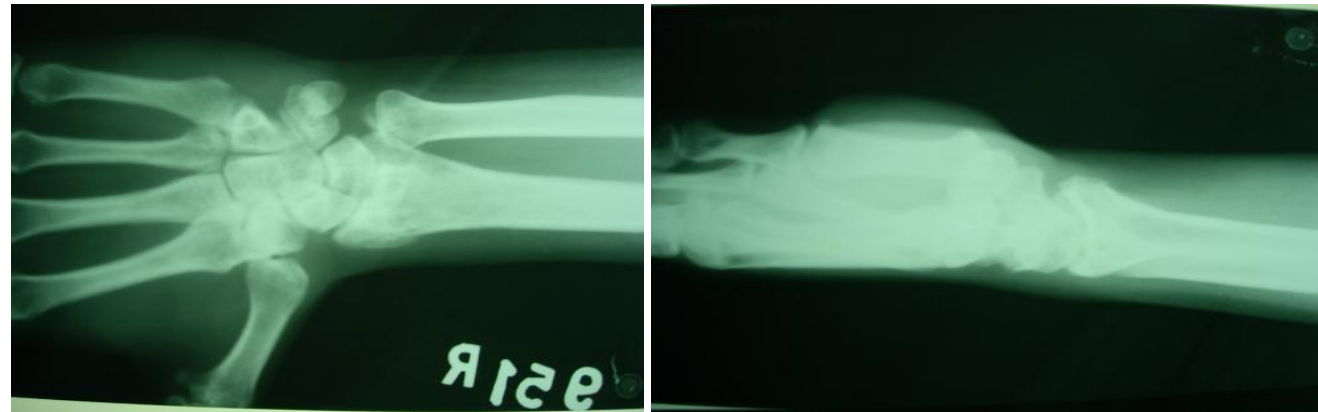

6-Month-Old X-Ray Ap And Lateral

\section{External Fixator Fixation}

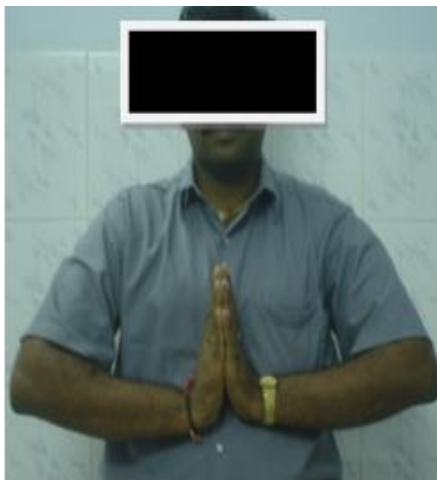

Dorsiflexion

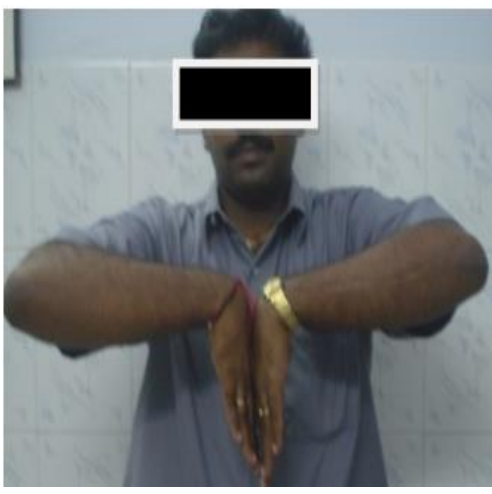

Palmarflexion

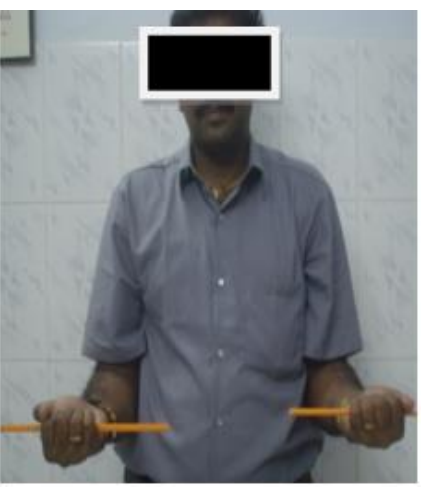

Supination

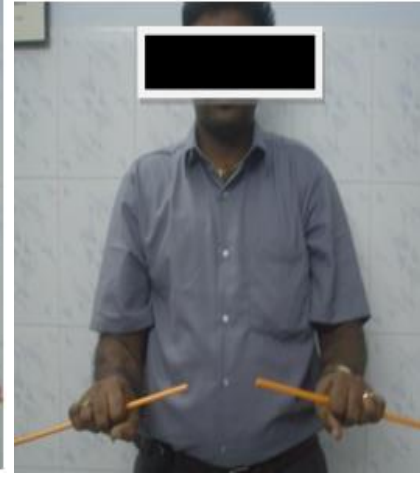

Pronation
AGE Distribution: Affected between age group of $20-58$ years, Majority of our patients were in the age group of 21-40 years and Mean age was 37.3 years.

SEX Distribution: Out of 30 patients, 20(67\%) were males and $10(33 \%)$ were females.

Mode of Injury: High velocity injuries constitute 67\% (20) case $\&$ rest all low velocity injuries.

Distribution Of Type Of Fracture: Based on Frykman's type of fracture ${ }^{[9]}$, in our series, Type III constituting about $13(43 \%)$ cases followed by type VIII 10 ( $33 \%)$ cases and type VII 7 (23\%) cases respectively

\section{Duration of external fixation:}

Duration of the external fixator in situ was for 5-6 weeks in $80 \%$ \& in $20 \%$ of cases external fixator was left in place for 7-8 weeks. Mean duration of external fixator application was 6 weeks.

Follow up: Most of our cases were followed up for a minimum period of 6 months. Average duration of follow up was 37 weeks.
Table 1: Average range of movement achieved after 6 months

\begin{tabular}{|c|c|}
\hline Movements & Average movement \\
\hline Dorsiflexion & $60^{0}$ \\
\hline Palmar flexion & $53^{0}$ \\
\hline Radial deviation & $15^{0}$ \\
\hline Ulnar deviation & $25^{0}$ \\
\hline Supination & $74^{0}$ \\
\hline Pronation & $70^{0}$ \\
\hline
\end{tabular}

Table 2: Complications

\begin{tabular}{|c|c|}
\hline Complications & No of cases \\
\hline Residual pain & 12 \\
\hline Dorsal angulation & 6 \\
\hline Pin tract infection & 0 \\
\hline Pin loosening & 1 \\
\hline Restricted wrist movements & 6 \\
\hline Finger stiffness & 3 \\
\hline Arthritis & 0 \\
\hline Distal radioulnar instability & 0 \\
\hline Sudeck's Dystrophy & 1 \\
\hline Carpal tunnel syndrome & 0 \\
\hline Non union & 0 \\
\hline
\end{tabular}


In our study we noticed 12 cases of residual wrist pain which was mild to moderate and was treated by analgesics alone. Pin tract infection was not seen. Restricted wrist movements and finger stiffness was present in cases of metaphyseal communition and in patients who were not compliant for physiotherapy. One case had mild Sudeck's dystrophy which responded to aggressive physiotherapy.

\section{Results}

Results were assessed as per De merit point system of Gartland and Werley (modified by Sarmiento 1975) ${ }^{[10]}$ for functional results at the end of 6 months of follow up.

1. Excellent: $12(40 \%)$ patients had no pain, no deformity, there was no restriction of movement of wrist and forearm. They were rated as excellent.

2. Good: $13(43.3 \%)$ patients had no deformity of the wrist but had some limitation of wrist movements. They were rated as Good.

3. Fair: $3(10 \%)$ patients had pain, limitation of movement at the wrist that was less than $50 \%$ of that of normal. In this group 3 patients had ulnar styloid prominence and the result was rated as fair.

4. Poor: $2(6.7 \%)$ patients had dinner fork deformity with almost stiff wrist and finger, the result was rated as poor.

\section{Discussion}

It must be emphasized that this study is only short term follow up with average of 37 weeks and the discussion that follows is essentially a preliminary assessment.

The aim of this study is to evaluate the results of external fixator for intra-articular fractures of distal end radius. Most distal radial fractures are treated with closed reduction and plaster immobilistion.

We treated 30 patients of intraarticular fracture of distal end radius in adults by wrist spanning external fixation from august 2018 to July 2020.

Patients ranged from 20-58 years and the mean age was 37.3 years

Higher incidence in 4 th decade $\&$ probably is due to active life style which is prone for accidents and resulting in high velocity injuries.

The incidence of fractures in our study was more common in males $20 / 30(67 \%)$ which can be attributed to the risk of injury due to occupational and ambulant life led by them, another reason for high incidence of cases in males may be due to high susceptibility to injury and easy accessibility to health facilities.

Out of 30 patients in $67 \%$ of our cases were high velocity injuries \& rest of all low velocity accidents.

As far as distribution of fractures according to Frykman [9] classification our indications for fracture of distal radius for external fixation are comparable to that of other standard studies. Most of our cases had a higher Frykman's type with Type III constituting 43\%. This is in concordance with studies by Nagi ${ }^{[2]}$, Leung ${ }^{[11]}$, Aggarwal ${ }^{[12]}$, Cooney ${ }^{[13]}$ and David Wei ${ }^{[14]}$.

The average period of immobilization in our study was shorter (6 weeks) as advised by Nagi et al. ${ }^{[2]}$ compared to that of Gunaki RB et al. ${ }^{[15]}$ where in it was 7.2 weeks. It was peculiarly noted that severely comminuted fractures and Frykman's type VIII required longer duration of immobilization.

The radial shortening due to loss of reduction was measured as the difference between initial post reduction and final $\mathrm{X}$ ray made for each patient as suggested by Cooney et al. (1979)13 In our series average loss of radial length was $2.53 \mathrm{~mm}$, slightly higher compared to $2.13 \mathrm{~mm}$ in David Wei et al. (2009) ${ }^{[14]}$. It was also noted that loss of radial length increases with Type VII \& VIII fractures.

Radial length is one of the crucial factors for regaining good wrist function. $4 \mathrm{~mm}-6 \mathrm{~mm}$ shortening compromises DRUJ (Collins 1993) ${ }^{[16]}$.

The residual tilt depended upon extent of dorsal angulation before reduction and adequacy of restoration of palmar tilt after reduction. Even small change in palmar tilt leads to radio carpal dysfunction as suggested by Taleisnik ${ }^{[17]}$ and

Causes midcarpal instabilities due to change in load distribution ${ }^{[15]}$

Even slight dorsal tilt increases dorsiflexion and decrease in palmar flexion because of shift of flexion-extension towards dorsal aspect.

Residual dorsal tilt $<10^{0}$ is acceptable. Excellent function of wrist is achieved even if normal $11^{0}$ palmar tilt is not achieved because of biomechanics of wrist. Inability of achievement of palmar tilt is short coming of uniplanar external fixation which provides ligamentotaxis in one plane this is confirmed by cadaveric study of intra-articular fractures by Bartosh and Saldana ${ }^{[18]}$. This short coming is overcome by multi planar ligamentotaxis and non bridging external fixation which

Provides facility for palmar translocation of fracture fragments without positioning of wrist in extreme flexion.

Knirk and Jupiter ${ }^{[19]}$ (1986) reported evidence of arthritis in $100 \%$ of cases with articular step of $2 \mathrm{~mm}$ at the time of union and incidence of $11 \%$ the wrist with congruous surface or $<2 \mathrm{~mm}$. This $11 \%$ was attributed to damage sustained to articular surface at the time of injury.

In our cases with articular step off $\geq 2 \mathrm{~mm}$ ( 2 cases), we did not observe any arthritic changes probably due to shorter duration of follow up.

Table 3: Comparison of range of movement of wrist

\begin{tabular}{|c|c|c|c|c|c|}
\hline Movement & Our Study & Gunakietal $^{[15]} \mathbf{( 1 9 8 9 )}$ & David Wei $^{[14]}$ & Minimum for normal function (Sarmiento 1975) & normal \\
\hline Dorsi Flexion & $60^{0}$ & $59^{0}$ & $66^{0}$ & $45^{0}$ & $70^{0}$ \\
\hline Palmar Flexion & $53^{0}$ & $52^{0}$ & $63^{0}$ & $30^{0}$ & $60^{0}$ \\
\hline Radial Deviation & $15^{0}$ & $18.83^{0}$ & $14^{0}$ & $15^{0}$ & $25^{0}$ \\
\hline Ulnar Deviation & $25^{0}$ & $23.5^{0}$ & $33^{0}$ & $50^{0}$ & $30^{0}$ \\
\hline Supination & $74^{0}$ & $75.16^{0}$ & $68^{0}$ & $50^{0}$ & $85^{0}$ \\
\hline Pronation & $70^{0}$ & $73.83^{0}$ & $68^{0}$ & $85^{0}$ \\
\hline
\end{tabular}

It is evident that average range of wrist movement achieved in present study at final follow up were more than maximum requirements for daily activities (Sarmiento 1975) ${ }^{[10]}$, are comparable with Gunaki RB et al. (1998) ${ }^{[15]}$ study and David wei (2009) ${ }^{[14]}$.

Grip strength was measured subjectively and with sphygmomanometer. It is also important to note that normally grip strength in dominant hand is $15 \%$ > in non dominant hand. In our study we found grip strength to be significantly reduced in 6 / 30 cases $(20 \%)$ whereas that in Gunaki RB et al. ${ }^{[15]}$ (1998) the grip strength was reduced in 4/30 cases $(13.3 \%)$. In David Wei ${ }^{[14]}$ grip strength reduced is $31 \%$. The average grip strength regained was $80 \%$ of normal during the study period. 
In complications, the lower incidence of pin related complications (pin tract infection 0 cases, pin loosening 1 cases) can be explained probably due to limited open technique of external fixator application as advocated by Seitz et al. (1993) ${ }^{[7]}$.

Residual wrist pain was seen in 12 patients most of which was mild and reproduced on exertion but it was not disabling as far as activities of daily living was concerned. Restricted wrist joint movements were seen in 6 patients and finger stiffness in
3 patients, this can be due to open fracture and non adherence of patient to vigorous rehabilitation program. Mild form of Sudeck's dystrophy was noted in 1case which subsided with physiotherapy and analgesics. None of our patients had carpal tunnel syndrome or non union. Results were assessed as per De merit point system of Gartland and Werley (modified by Sarmiento 1975) ${ }^{[10]}$ for functional results at the end of 6 months of follow up.

Table 4: Functional results compared with other standard studies

\begin{tabular}{|c|c|c|c|}
\hline Study group & Excellent to good & Fair to poor & Total \\
\hline Cooney WP et al. ${ }^{[13]}(1979)$ & $85 \%$ & $15 \%$ & 130 \\
\hline Leung KS et al. ${ }^{[11]}(1989)$ & $80 \%$ & $20 \%$ & 72 \\
\hline Jakim I et al. ${ }^{[20]}(1991)$ & $83 \%$ & $17 \%$ & 169 \\
\hline Gunaki RB et al. ${ }^{[15]}(1998)$ & $86 \%$ & $14 \%$ & 30 \\
\hline Kleina W et al. ${ }^{[2]]}(2000)$ & $87 \%$ & $13 \%$ & 103 \\
\hline Nagi ON et al. ${ }^{[2]}(2004)$ & $74.28 \%$ & $25.72 \%$ & 35 \\
\hline Our study & $83.3 \%$ & $16.7 \%$ & 30 \\
\hline
\end{tabular}

\section{Conclusion}

This series concludes that in younger age group $[<50]$, ligamentotaxis by external fixation.

Consistently results in a favourable outcome in the management of intra-articular fractures of distal end radius.

The successful use of external fixator for intraarticular fracture of distal end radius requires careful assessment of fracture pattern, appropriate patient selection, meticulous surgical techniques, appropriate choice of fixation, judicious augmentation with internal fixation and bone grafting, careful post-operative monitoring and aggressive early institution of rehabilitation. The success not only depends on the anatomical restoration of the articular surface. It also depends on the associated soft tissue injuries and articular damage.

Studies having a larger number of fractures treated with different modalities and longer duration are needed to evaluate the outcome of intra-articular fractures of distal end radius. But the early outcomes are encouraging.

\section{Acknowledgements: None}

\section{References}

1. Ark J, Jupiter JB. The rationale for precise management of distal radius fractures. Orthop Clin North Am. 1993;24(2):205-210.

2. Nagi ON, Dhillon MS, Aggarwal S, Deogaonkar KJ. External fixators for intra-articular distal radius fractures. Indian Journal of Orthopaedics 2004;38:19-22.

3. Jupiter JB. Current concepts review - Fractures of the distal end of the radius. J Bone Joint Surg (Am). 1991;73-A:461-469.

4. Melone CP Jr. Articular fractures of the distal Radius. Orthop Clin North Am 1984;15:217- 236.

5. Melone CP Jr. Distal radius fractures: Patterns of articular fragmentation. Orthop Clin North Am. 1993;24(2):239-253.

6. Simic PM, Weiland AJ. Fractures of the distal aspect of the Radius: Changes in Treatment Over the past two decades. J Bone Joint Surg (Am). 2003;85-A:552-564.

7. Seitz WH Jr. External fixation of distal radius fractures: Indications and Technical Principles. Orthop Clin North Am. 1993;24(2):255-264.

8. Raskin KB, Melone CP Jr. Unstable articular fractures of the distal Radius: Comparative techniques of Ligamentotaxis. Orthop Clin North Am 1993;24(2):275286.

9. Frykman G. Fracture of the Distal Radius Including
Sequelae-Shoulder- Hand-Finger Syndrome, Disturbance in the Distal Radio-Ulnar Joint, and Impairment of Nerve Function: A Clinical and Experimental Study. Acta Orthop Scand 1967;108(Suppl):1-153.

10. Sarmiento A, Pratt GW, Berry NC, Sinclair WF. Colles' Fractures: Functional Bracing in Supination. J Bone Joint Surg 1975; 57-A:311-317.

11. Leung KS, Shen WY, Leung PC, Kinninmonth AW, Chang JC, Chan GP. Ligamentotaxis and bone grafting for comminuted fractures of the distal radius. $\mathrm{J}$ Bone Joint Surg 1989;71-B(5):838-842.

12. Aggarwal A, Rastogi A. External fixation for intra articular fracture distal end radius-a prospective study between bridging and non-bridging fixator. Indian Journal of Orthopaedics. 2004;38(1):23-27.

13. Cooney WP, Linscheid RL, Dobyns JH. External Pin Fixation for Unstable Colles' Fractures. J Bone Joint Surg 1979;61-A:840-845.

14. Unstable Distal Radial Fractures Treated with External Fixation, a Radial Column Plate, or a Volar Plate. A Prospective Randomized tial Rosenwasser David H. Wei, Noah M. Raizman, Clement J. Bottino, Charles M. Jobin, Robert J. Strauch and Melvin P. J Bone Joint Surg Am. 2009;91:1568-1577. doi:10.2106/JBJS.H.00722.

15. Gunaki RB, Ranka RP. Management of fractures of distal third of radius. Indian Journal of Orthopaedics 1998;32(4):242-246.

16. Collins DC. Management and rehabilitation of distal radius fractures. Ortho Clin North Am 1993;24(2):365378.

17. Taleisnik J. Midcarpal instability caused by malunited fractures of the distal radius. J Hand Surg 1984;9(3):350357.

18. Bartosh RA, Saldana MJ. Intraarticular fractures of the distal radius: a cadaveric study to determine if ligamentotaxis restores radiopalmar tilt. J Hand Surg 1990;15(1):18-21.

19. Knirk JL, Jupiter JB. Intra-Articular Fractures of the Distal End of the Radius in Young Adults. J Bone Joint Surg 1986;68-A:647-659.

20. Jakim I, Pieterse HS, Sweet MB. External fixation for intra-articular fractures of the distal radius. J Bone Joint Surg 1991;73-B(2):302-306.

21. Kleina W, DeÂeb W, Riegerc H, Neumanna HS, Joostenc U. Results of transarticular fixator application in distal radius fractures. Injury 2000;31:71-77. 